\title{
Absence of Dickkopf (Dkk)-3 protein expression is correlated with longer disease-free survival and lower incidence of metastasis in head and neck squamous cell carcinoma
}

\author{
NAOKI KATASE ${ }^{1}$, MATHIEU LEFEUVRE ${ }^{1}$, MEHMET GUNDUZ ${ }^{1,2}$, ESRA GUNDUZ $^{3}$, \\ LEVENT BEKIR BEDER ${ }^{4}$, REIDAR GRENMAN ${ }^{5}$, MASAE FUJII ${ }^{1}$, RYO TAMAMURA ${ }^{1}$, \\ HIDETSUGU TSUJIGIWA $^{1}$ and HITOSHI NAGATSUKA ${ }^{1}$
}

\begin{abstract}
${ }^{1}$ Department of Oral Pathology and Medicine, Graduate school of Medicine, Dentistry and Pharmaceutical Sciences, Okayama University, Okayama, Japan; Departments of ${ }^{2}$ Otolaryngology Head and Neck Surgery, and ${ }^{3}$ Medical Genetics, Faculty of Medicine, Fatih University, Ankara, Turkey; ${ }^{4}$ Department of Otolaryngology Head and Neck Surgery, Wakayama Medical University, Wakayama, Japan; ${ }^{5}$ Department of Otorhinolaryngology and Head and Neck Surgery, Turku University Central Hospital and Department of Medical Biochemistry and Molecular Biology, University of Turku and University Central Hospital, Turku, Finland
\end{abstract}

Received June 9, 2011; Accepted November 2, 2011

DOI: $10.3892 / \mathrm{ol} .2011 .473$

\begin{abstract}
Head and neck squamous cell carcinoma (HNSCC) is one of the most frequently occurring types of cancer worldwide. We focused on the fact that the aberrant function of $\mathrm{Wnt} / \beta$-catenin signaling is a frequent event in malignancies. Dickkopf (Dkk)-3 is a major negative regulator of Wnt/ $\beta$-catenin signaling, which is a known tumor suppressor and is down-regulated in various types of cancer. However, the expression profile of the Dkk-3 protein in HNSCC has not yet been reported. The present study was conducted to investigate Dkk-3 protein expression in 90 cases of HNSCC tissue samples and HNSCC-derived cell lines. In contrast to findings available on other types of cancer, the Western blot analysis revealed that HNSCC cell lines expressed the Dkk-3 protein. In immunohistochemistry, 76 cases (84.4\%) out of 90 tissue samples were Dkk-3-positive, whereas only 14 cases (15.6\%) were negative. Notably, survival analysis showed that the Dkk-3 (-) group exhibited significantly longer disease-free survival $(\mathrm{p}=0.038)$, metastasis-free survival $(\mathrm{p}=0.013)$ and longer overall survival $(\mathrm{p}=0.155)$. The results showed that the Dkk-3 protein was dominantly expressed and may be involved in carcinogenesis and metastasis in HNSCC. Moreover, the findings suggest that the function of Dkk-3 differs depending on the tissue of origin, and that it may exert an oncogenic function in HNSCC.
\end{abstract}

Correspondence to: Dr Naoki Katase, Department of Oral Pathology and Medicine, Graduate school of Medicine, Dentistry and Pharmaceutical Sciences, Okayama University, 2-5-1 Shikata-cho, Kita-ku, Okayama, 700-8525 Japan

E-mail:katase-n@cc.okayama-u.ac.jp

Key words: head and neck squamous cell carcinoma, Dkk-3, immunohistochemistry

\section{Introduction}

Head and neck squamous cell carcinoma (HNSCC) is a frequently occurring cancer worldwide. HNSCC exhibits heterogeneous characteristics: some HNSCC exhibit a welldifferentiated, low invasive, bland phenotype, whereas others exhibit a highly invasive phenotype, often with lymph nodal and/or distant metastasis, and the sensitivity to chemotherapy or radiation therapy varies according to the individual case. Moreover, as background risk factors, the involvement of environmental exposure of the patient, including tobacco smoking and alcohol consumption, make it more complex to understand the biological behavior of HNSCC.

HNSCC occurs as a result of cumulative genetic or epigenetic alterations in cancer-related genes, oncogenes and tumor suppressor genes (TSGs). Despite recent advances in molecular pathology, little is known regarding the genes or pathways that play key roles in HNSCC (1). To establish a more concise understanding of the biological characteristics of HNSCC, our group has been working on a genome-wide analysis with the aim of identifying the genes that act as the principle drivers of carcinogenesis, invasion and metastasis. The focus has been on the abnormal function of the major tumor suppressor molecules. Previously, we reported on the decreased function in the ING family (2-6), and the possible tumor suppressor role of Dickkopf (Dkk)-3, which is the tumor suppressor against oncogenic Wnt/ $\beta$-catenin signaling in $\operatorname{HNSCC}(7,8)$.

$\mathrm{Wnt} / \beta$-catenin signaling is one of the most crucial pathways in carcinogenesis in HNSCC. Recent cancer stem cell research revealed that the side population, which includes cancer stem cells in HNSCC, demonstrates abnormal Wnt/ $\beta$-catenin signaling, and that such cells possess highly invasive potential (9). The Dkk family functions as a negative regulator of Wnt signaling, and thus acts as a tumor suppressor (10). As previously reported, the down-regulation of Dkk-3 in mRNA 
expression is observed as a common event in several types of malignancies, including glioma (11), hepatocellular carcinoma (12), breast cancer (13), melanoma (14), prostate (15) and gastrointestinal cancer (16). The decrease in mRNA expression induction may also decrease Dkk-3 protein expression, which may lead to the loss of tumor suppressor functions, resulting in carcinogenesis.

However, of note, the mRNA down-regulation of Dkk-3 may vary depending on the tissue of origin. For instance, Dkk3 mRNA expression is not decreased in certain esophageal squamous cell carcinoma cell lines (16). Furthermore, Dkk-3 protein expression is conserved in esophageal squamous cell carcinoma tissue samples (17), indicating the existence of crucial and specific roles of Dkk-3 in squamous epithelium origin, while the protein expression status of Dkk-3 in HNSCC has yet to be reported.

In the present study, we investigated the protein expression of Dkk-3 in a HNSCC tissue sample and HNSCC cell lines, as well as the correlation between the clinicopathological characteristics and patient prognosis by statistical analysis. We report notable findings regarding Dkk-3 expression and discuss its possible role in HNSCC carcinogenesis and progression.

\section{Materials and methods}

Tissue samples and patients. In total, 90 cases of HNSCC tissue samples and 10 cell lines were used for this study. The tissue sample was obtained from the Okayama University Tumor bank (Professor Kenji Shimizu) and Okayama University Hospital Surgical Pathology Unit (Okayama, Japan) between 1994 and 2008. The details of the patient data, including gender, age, history of smoking, alcohol consumption, TNM staging, incidence of lymph nodal metastasis and the condition with or without chemotherapy or radiation therapy, are shown in Table I.

The patients included 63 males and 27 females. Follow-up duration periods were between 1 and 105 months. During follow-up, 13 patients with local cancer recurrence, 25 with lymph nodal/distant metastasis and 2 with both recurrence and metastasis, were observed. Of the 90 patients, 25 patients succumbed to cancer. The tumors were surgically excised from gingiva $(\mathrm{N}=23)$, buccal mucosa $(\mathrm{N}=10)$, the mouth floor $(\mathrm{N}=8)$, tongue $(\mathrm{N}=28)$, lower lip $(\mathrm{N}=1)$, larynx $(\mathrm{N}=8)$, hypopharynx $(\mathrm{N}=7)$, mesopharynx $(\mathrm{N}=4)$ and oropharynx $(\mathrm{N}=1)$ after informed consent was obtained from each patient. The tissue samples were fixed with $10 \%$ neutral-buffered formalin and processed for paraffin-embedded sections. Serial sections $(4 \mu \mathrm{m})$ were used for hematoxylin and eosin (H\&E) sections and immunohistochemical analysis.

Cell lines. The cell lines HSC-2, HSC-3, HSC-4 and Ca9-22 were provided by RIKEN BRC through the National BioResource Project of the The Ministry of Education, Culture, Sports, Science and Technology (MEXT), Japan. The cell lines UT-SCC-12A, UT-SCC-12B, UT-SCC-16A, UT-SCC-16B, UT-SCC-60A and UT-SCC-60B, which were paired and originally established cell lines from the primary and metastatic cancers of the same patients, were kindly provided by Dr Reidar Grenman, University of Turku, Finland.
Table I. Clinicopathological characteristics of patients.

\begin{tabular}{|c|c|c|}
\hline Parameter & Number & $\%$ \\
\hline Age (years) mean $\pm \mathrm{SD}$ & $67.28 \pm 11.28$ & \\
\hline \multicolumn{3}{|l|}{ Gender } \\
\hline Male & 63 & 70.0 \\
\hline Female & 27 & 30.0 \\
\hline \multicolumn{3}{|l|}{ Tumor site } \\
\hline Tongue & 28 & 31.1 \\
\hline Gingiva & 23 & 25.6 \\
\hline Buccal mucosa & 10 & 11.1 \\
\hline Mouth floor & 8 & 8.9 \\
\hline Larynx & 8 & 8.9 \\
\hline Hypopharynx & 7 & 7.8 \\
\hline Mesopharynx & 4 & 4.4 \\
\hline Oropharynx & 1 & 1.1 \\
\hline Lower lip & 1 & 1.1 \\
\hline \multicolumn{3}{|l|}{ T stage } \\
\hline $\mathrm{T} 1$ & 16 & 17.8 \\
\hline $\mathrm{T} 2$ & 33 & 36.7 \\
\hline $\mathrm{T} 3$ & 17 & 18.9 \\
\hline $\mathrm{T} 4$ & 24 & 26.7 \\
\hline \multicolumn{3}{|l|}{$\mathrm{N}$ stage } \\
\hline No & 49 & 54.4 \\
\hline N1 & 17 & 18.9 \\
\hline $\mathrm{N} 2$ & 21 & 23.3 \\
\hline N3 & 3 & 3.3 \\
\hline \multicolumn{3}{|l|}{ TNM stage } \\
\hline I & 14 & 15.6 \\
\hline II & 22 & 24.4 \\
\hline III & 17 & 18.9 \\
\hline IV & 37 & 41.1 \\
\hline \multicolumn{3}{|l|}{ Differentiation } \\
\hline Well & 53 & 58.9 \\
\hline Moderate & 26 & 28.9 \\
\hline Poor & 11 & 12.2 \\
\hline
\end{tabular}

SD, standard deviation.

The cell lines were maintained in Dulbecco's modified Eagle's medium (Gibco, Tokyo, Japan) with antibiotics and an antimycotic agent, including $100 \mathrm{U} / \mathrm{ml}$ penicillin, $100 \mu \mathrm{g} / \mathrm{ml}$ streptomycin and $25 \mathrm{mg} / \mathrm{ml}$ amphotericin $\mathrm{B}$ (Gibco), in a $\mathrm{CO}_{2}$ incubator with an atmosphere of $95 \%$ air plus $5 \% \mathrm{CO}_{2}$ at $37^{\circ} \mathrm{C}$. When the cells became confluent, total protein was extracted for Western blotting as reported in a previous study (18).

Western blotting. Western blotting was performed according to the usual procedure. Cell extracts were boiled for $5 \mathrm{~min}$ in sodium dodecyl sulfate (SDS) gel-loading buffer $(0.1 \mathrm{M}$ Tris-HCl, pH 6.8, 20\% glycerol, 2.5\% SDS, $0.05 \%$ bromophenol blue and $5 \% \beta$-mercaptoethanol). Equal amounts of each protein sample were then loaded and separated on $12.5 \%$ 
SDS-polyacrylamide gels and blotted onto polyvinylidene difluoride (PVDF) membranes. Following the blockade of nonspecific binding by soaking the PVDF membranes in 5\% skim milk, proteins were detected using anti-Dkk-3 (R\&D Systems, Minneapolis, MN, USA) and anti- $\beta$-actin (Abcam, Cambridge, MA, USA). Proteins were visualized using the ECL Plus Western blotting detection system (Amersham, Arlington Heights, IL, USA) according to the manufacturer's instructions.

Immunohistochemistry. Immunohistochemistry was carried out according to the manufacturer's instructions using goat polyclonal antibody against human Dkk-3 (R\&D Systems). Briefly, cut tissue sections were deparaffinized in xylene for $20 \mathrm{~min}$, and then dehydrated in graded alcohol solutions. The endogenous peroxidase activity was blocked by immersing the sections in $3 \% \mathrm{H}_{2} \mathrm{O}_{2}$ in methanol for $30 \mathrm{~min}$. For antigen retrieval, the sections were heated in $0.01 \mathrm{~mol} / \mathrm{l}$ citrate buffer (pH 6.0) for $15 \mathrm{~min}$. The sections were then treated with $10 \%$ normal rabbit serum for $30 \mathrm{~min}$, followed by incubation with primary Dkk-3 antibody at $4{ }^{\circ} \mathrm{C}$ overnight. Identification of an immunoreactive site was achieved by subsequent incubation with a biotinylated secondary antibody for $30 \mathrm{~min}$, followed by detection using the avidin-biotin complex (ABC) method (Vectastain ABC kit; Funakoshi, Tokyo, Japan). Sections were then reacted with $0.02 \% 3,3^{\prime}$-diaminobenzidine (Wako, Osaka, Japan) with $0.006 \% \mathrm{H}_{2} \mathrm{O}_{2}$ in $0.05 \mathrm{ml} / 1$ Tris- $\mathrm{HCl}(\mathrm{pH} 7.6)$. The sections were counterstained by Mayer's hematoxylin and mounted. The specimens were checked by two pathologists, and scored as positive if there was any positive reaction, and otherwise scored as negative.

Statistical analysis. Pearson's Chi-square test and Fisher's exact test were used to evaluate the correlation between the Dkk-3 protein expression and clinicopathological characteristics. The Kaplan-Meier analysis was performed to determine the survival analysis. For comparison of survival between the Dkk-3positive and -negative groups, the log-rank test was used. The duration of disease-free survival (DFS) was determined from the day following surgery to the initial recurrence or metastasis evaluated by clinical examination. Overall survival (OS) in months was calculated from the day following surgery to the last follow-up appointment. To determine the detailed involvement of Dkk-3 expression in DFS, metastasis-free survival (MFS) and recurrence-free survival (RFS) were also examined. MFS was determined from the day following surgery to the initial metastasis-evaluated clinical examination. RFS was determined from the day following surgery to the initial recurrence of the surgically excised cancer. For multivariate analysis, a Cox proportional hazard model was used. Computations were performed using PASW Statistics 18 (SPSS Inc. Chicago, IL, USA). $\mathrm{P}<0.05$ was considered statistically significant.

\section{Results}

Expression of Dkk-3 in HNSCC. Results of the Western blot analysis revealed that the HNSCC-derived cell lines expressed Dkk-3 protein to a varying degree. The HSC-4 and Ca9-22 cells exhibited intense Dkk-3 expression, whereas the UT-SCC-12A and UT-SCC-12B cells were comparatively weak. UT-SCC12A/12B, UT-SCC-16A/16B and UT-SCC-60A/60B were

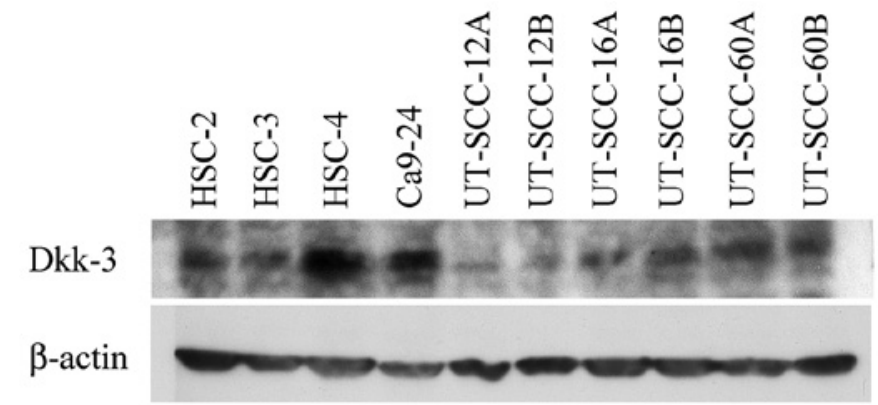

Figure 1. Western blot analysis shows that the cancer cells expressed Dkk-3 protein to varying degrees. Notably, cancer cells expressed Dkk-3 regardless of primary or metastatic cancer of origin. $\beta$-actin was used as a control.

paired cell lines, which were derived from the primary cancer/ metastatic cancer of the same patients. Of note, the paired cell lines expressed Dkk-3 regardless of their primary/metastatic origin (Fig. 1).

Dkk-3 expression was also detected in the tissue samples. Using immunohistochemistry, the majority of the HNSCC tissue samples exhibited a positive reaction for Dkk-3. Of the 90 cases, 76 cases $(84.4 \%)$ were positive, whereas only 14 cases (14.6\%) were negative. A positive reaction was detected in the invasive cancer nests and the dysplastic epithelium continuing to the cancer. Dkk-3 was present in the cytoplasm and plasma membrane of the tumor cells as well as in blood vessels around the tumor nest and in the lymphatic vessels, but no nuclear expression was observed. The expression of Dkk-3 in the metastatic lymph node was also examined in certain cases. Intense Dkk-3 expression was also observed in tumor cells in the metastatic lymph nodes (Fig. 2).

Dkk-3 expression and clinicopathological characteristics. The relationship between Dkk-3 expression and various clinicopathological characteristics was examined. No significant association was found between Dkk-3 and any of the parameters investigated (Table II). However, a tendency of correlation was shown for smoking habits ( $\mathrm{p}=0.170)$, TNM stage $(\mathrm{p}=0.154)$ and existence of the chemotherapy $(\mathrm{p}=0.097)$. In relation to smoking, Dkk-3-positive expression was observed in 37 cases out of 44 smoking patients (84.1\%), whereas the non-smoking patient positivity was $68.8 \%$ (11/16 cases). Eight patients out of 14 cases $(57.1 \%)$ were from early TNM stage (I-II), whereas $48(63.2 \%)$ of the Dkk-3-positive cases $(\mathrm{N}=76)$ were from late TNM stage (III-IV). As for chemotherapy, the majority of the Dkk-3-positive patients (54/75 cases, $88.5 \%$ ) did not undergo chemotherapy. Of note, the Dkk-3 (-) group included no cases of metastasis and only 2 cases $(2 / 13,15.4 \%)$ of local recurrence, whereas 25 patients with lymph nodal/distant metastasis and 2 patients with local recurrence and metastasis belong to the Dkk-3 (+) group. The number of patients who succumbed to the disease in the follow-up period in the Dkk-3 (+) and Dkk-3 (-) groups were 23/25 (92.0\%) and 2/25 (8.0\%), respectively.

Dkk-3 expression and survival. Survival analysis by the Kaplan-Meier curves indicated that patients without Dkk-3 expression have a significantly longer DFS than patients with Dkk-3 expression $(\mathrm{p}=0.038)$. No significant association was 
Table II. Relationship between Dkk-3 protein expression and clinicopathological characteristics.

\begin{tabular}{|c|c|c|c|}
\hline \multirow[t]{2}{*}{ Parameters } & \multicolumn{2}{|c|}{ Dkk-3 expression } & \multirow[b]{2}{*}{ p-value } \\
\hline & $\begin{array}{c}\text { Dkk-3 (+) } \\
(\mathrm{N}=76)\end{array}$ & $\begin{array}{c}\text { Dkk-3 (-) } \\
(\mathrm{N}=14)\end{array}$ & \\
\hline \multicolumn{4}{|l|}{ Gender } \\
\hline Male & $52(68.4 \%)$ & $11(78.6 \%)$ & 0.338 \\
\hline Female & $24(31.6 \%)$ & $3(21.4 \%)$ & \\
\hline \multicolumn{4}{|l|}{ Age } \\
\hline$<65$ & $24(31.6 \%)$ & $4(28.6 \%)$ & 1.000 \\
\hline$\geq 65$ & $52(68.4 \%)$ & $10(71.4 \%)$ & \\
\hline \multicolumn{4}{|l|}{ Smoking $^{\text {a }}$} \\
\hline Yes & $37(77.1 \%)$ & $7(58.3 \%)$ & 0.170 \\
\hline No & $11(22.9 \%)$ & $5(41.7 \%)$ & \\
\hline \multicolumn{4}{|c|}{ Alcohol consumption ${ }^{\mathrm{a}}$} \\
\hline Yes & $31(64.6 \%)$ & $7(58.3 \%)$ & 0.466 \\
\hline No & $17(35.4 \%)$ & $5(41.7 \%)$ & \\
\hline \multicolumn{4}{|l|}{ TNM stage } \\
\hline I-II & $28(36.8 \%)$ & $8(57.1 \%)$ & 0.154 \\
\hline III-IV & $48(63.2 \%)$ & $6(42.9 \%)$ & \\
\hline \multicolumn{4}{|l|}{ T stage } \\
\hline $\mathrm{T} 1-\mathrm{T} 2$ & $40(52.6 \%)$ & $9(64.3 \%)$ & 0.421 \\
\hline T3-T4 & $36(47.4 \%)$ & $5(35.7 \%)$ & \\
\hline \multicolumn{4}{|l|}{$\mathrm{N}$ stage } \\
\hline N (-) & $40(52.6 \%)$ & $9(64.3 \%)$ & 0.421 \\
\hline $\mathrm{N}(+)$ & $36(47.4 \%)$ & $5(35.7 \%)$ & \\
\hline \multicolumn{4}{|l|}{ Differentiation } \\
\hline Well & $43(56.6 \%)$ & $10(71.4 \%)$ & 0.299 \\
\hline Moderate-poor & $33(43.6 \%)$ & $4(28.6 \%)$ & \\
\hline \multicolumn{4}{|c|}{ Radiation therapy $^{\mathrm{a}}$} \\
\hline Yes & $22(29.7 \%)$ & $5(35.7 \%)$ & 0.438 \\
\hline No & $52(70.3 \%)$ & $9(64.3 \%)$ & \\
\hline \multicolumn{4}{|l|}{ Chemotherapy $^{\mathrm{a}}$} \\
\hline Yes & $21(28.0 \%)$ & $7(50.0 \%)$ & 0.097 \\
\hline No & $54(72.0)$ & $7(50.0 \%)$ & \\
\hline \multicolumn{4}{|c|}{ Previous cancer history ${ }^{a}$} \\
\hline Yes & $18(25.0 \%)$ & $5(35.7 \%)$ & 0.300 \\
\hline No & $54(75.0 \%)$ & $9(64.3 \%)$ & \\
\hline
\end{tabular}

${ }^{a}$ Tumors with unknown situation for smoking $(\mathrm{N}=28)$, alcohol consumption $(\mathrm{N}=28)$, radiation therapy $(\mathrm{N}=2)$, chemotherapy $(\mathrm{N}=1)$ and previous cancer history $(\mathrm{N}=3)$ were not included in the evaluation.

found between OS and Dkk-3 expression; however, similarly to DFS, patients without Dkk-3 expression presented a tendency for longer OS than those with Dkk-3 expression $(p=0.155)$. As for MFS and RFS, the Dkk-3 (-) group showed significantly longer MFS ( $\mathrm{p}=0.013)$, whereas no significant difference was found in RFS ( $\mathrm{p}=0.730$ ) (Fig. 3). The Cox proportional hazard model for survival analysis revealed that the Dkk-3 expression status was the independent prognostic marker for DFS $(\mathrm{p}=0.004), \mathrm{OS}(\mathrm{p}=0.001)$ and MFS $(\mathrm{p}=0.015)$ (Table III).

\section{Discussion}

HNSCC is an unmanageable cancer, which exhibits variation both biologically and clinically. Certain cases of HNSCC show a highly invasive phenotype, which gives rise to metastasis in lymph nodes and/or distant organs and exhibits chemoresistance, while others do not. To improve our understanding of the biological mechanisms of HNSCC, which may lead to the establishment of a new cancer therapy strategy, the search 

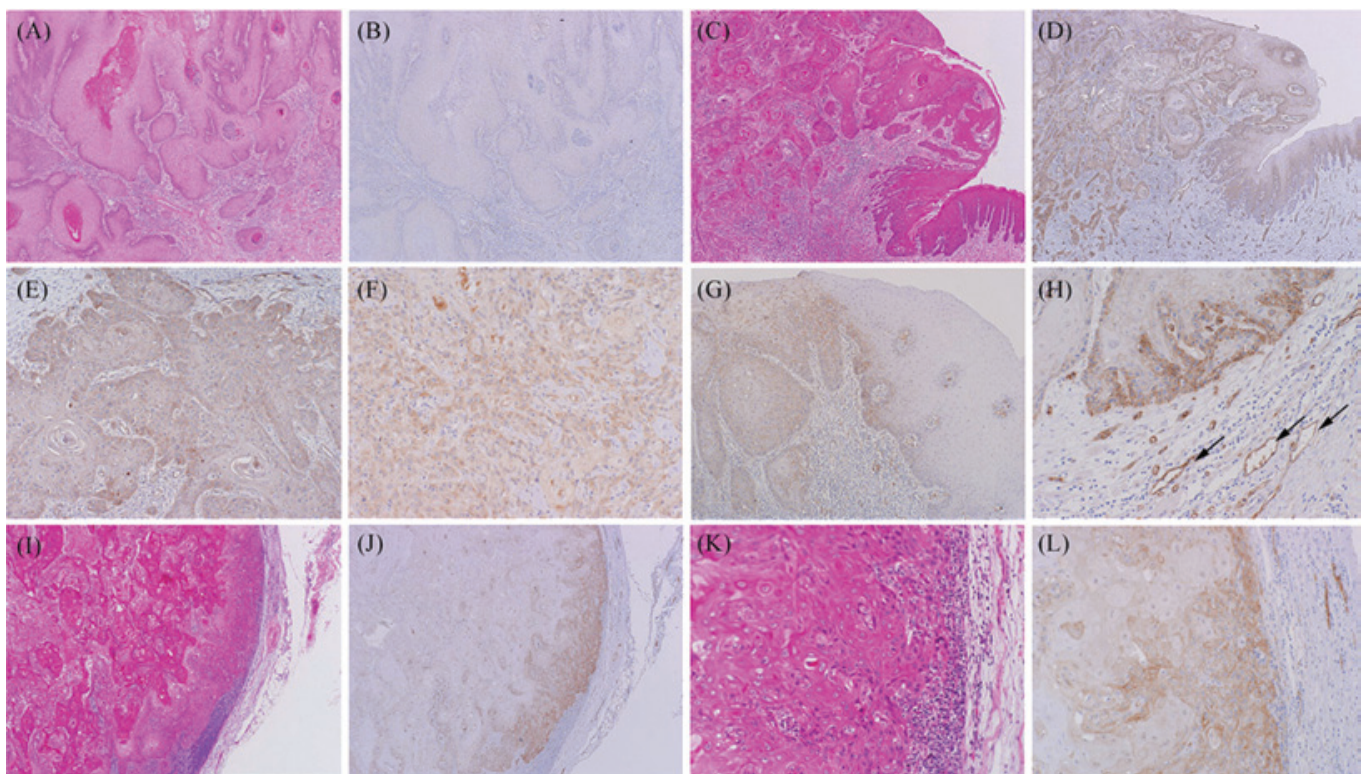

Figure 2. Dkk-3 protein expression was evaluated as negative (A and B) and positive (C and D). Dkk-3 protein expression was observed in the cytoplasm and plasma membrane of the cancer cells, regardless of histological differentiation (E and F, well-differentiated SCC and poorly differentiated SCC, respectively). (G) Normal and dysplastic epithelium, adjacent to the invasive cancer region, also expressed Dkk-3 to varying degrees. (H) Dkk-3 expression was also observed in adjacent microvessels around the cancer nests, including both blood vessels and lymphatic vessels (arrows). (I-K) Dkk-3 expression was observed in metastatic cancer cells of the lymph nodes. Original magnification: A-D, G, J and I, x40; E, F, H, K and L, x100, respectively. SCC, squamous cell carcinoma.

A

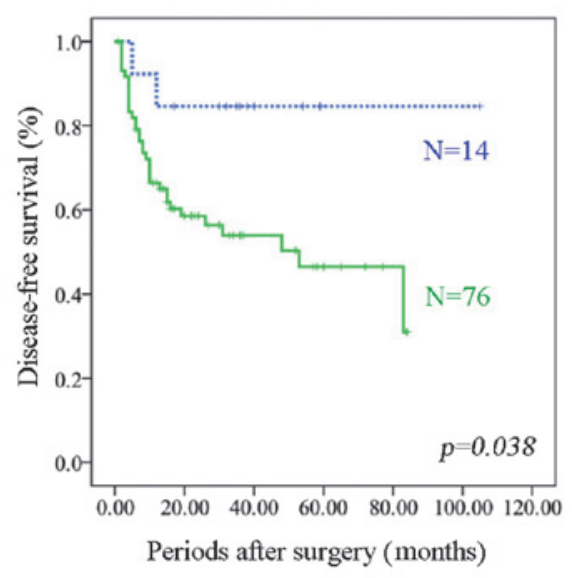

C

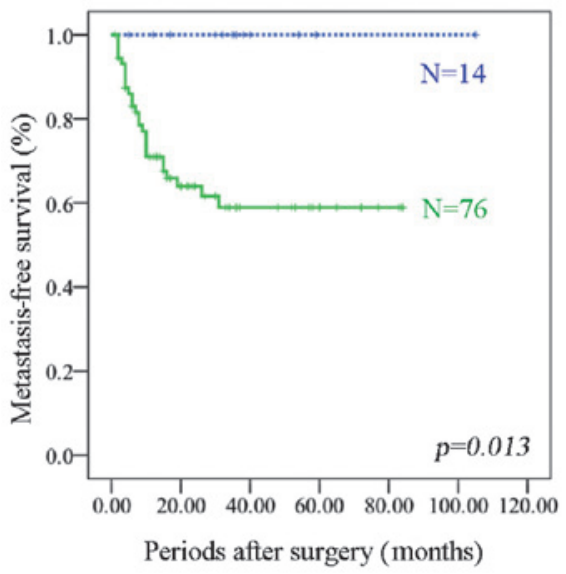

Negative

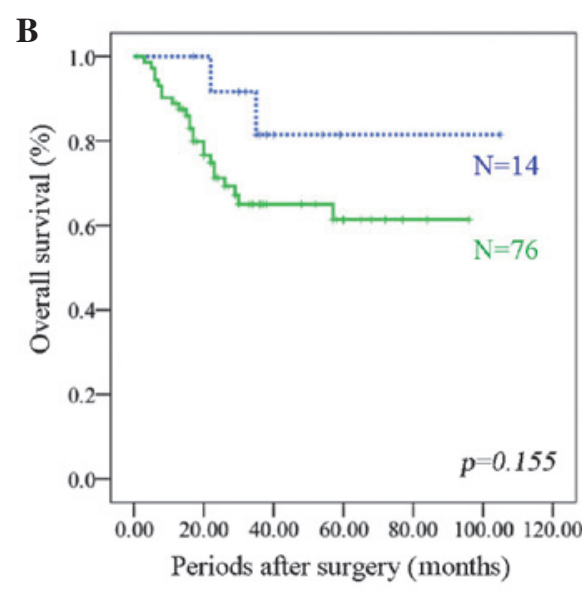

D

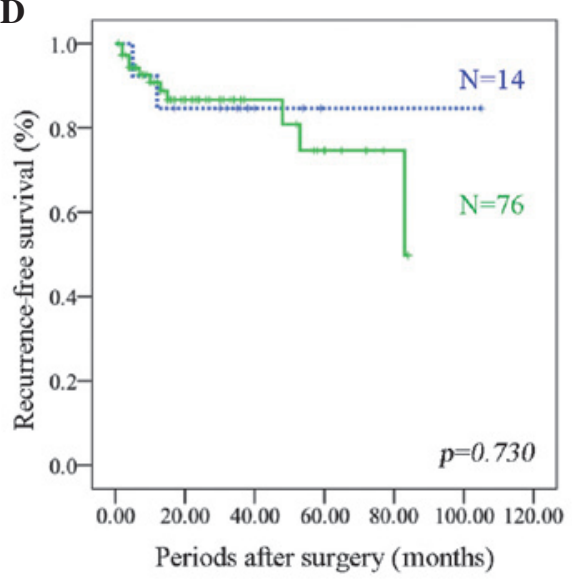

Negative-censored Positive-censored

Figure 3. (A) Survival analysis based on the Kaplan-Meier method revealed that the Dkk-3 negative group showed significantly longer disease-free survival. (B) Although there was no significance, the Dkk-3-negative group tended to show longer overall survival. (C) Notably, metastasis-free survival of the Dkk-3-negative group was significantly longer than that of the Dkk-3-positive group. (D) As for recurrence-free survival, there was no correlation between the Dkk-3-negative and -positive groups. 
Table III. Cox proportional hazard model for survival analysis.

\begin{tabular}{|c|c|c|c|c|c|c|c|c|}
\hline \multirow{3}{*}{ Variables } & \multicolumn{4}{|c|}{ Disease-free survival } & \multicolumn{4}{|c|}{ Overall survival } \\
\hline & \multirow[t]{2}{*}{$\mathrm{p}$-value } & \multirow[t]{2}{*}{ HR } & \multicolumn{2}{|c|}{$95 \% \mathrm{CI}$} & \multirow[t]{2}{*}{ p-value } & \multirow[t]{2}{*}{ HR } & \multicolumn{2}{|c|}{$95 \% \mathrm{CI}$} \\
\hline & & & Lower & Upper & & & Lower & Upper \\
\hline Gender & 0.440 & 1.881 & 0.378 & 9.344 & 0.332 & 2.565 & 0.383 & 17.199 \\
\hline Age & 0.285 & 0.578 & 0.212 & 1.579 & 0.340 & 0.594 & 0.204 & 1.733 \\
\hline Smoking & 0.696 & 1.399 & 0.259 & 7.550 & 0.767 & 1.320 & 0.210 & 8.308 \\
\hline Alcohol & 0.125 & 0.407 & 0.129 & 1.282 & 0.564 & 0.684 & 0.188 & 2.484 \\
\hline TNM stage & 0.923 & 0.000 & 0.000 & $2.95 \mathrm{E}+101$ & 0.929 & 0.000 & 0.000 & $2.1 \mathrm{E}+122$ \\
\hline T stage & 0.934 & 30233.381 & 0.000 & $1.6 \mathrm{E}+111$ & 0.942 & 56904.112 & 0.000 & $8.1 \mathrm{E}+132$ \\
\hline $\mathrm{N}$ stage & 0.198 & 3.234 & 0.540 & 19.354 & 0.095 & 6.755 & 0.716 & 63.733 \\
\hline Differentiation & 0.243 & 2.188 & 0.588 & 8.149 & 0.086 & 3.967 & 0.822 & 19.134 \\
\hline Radiation & 0.002 & 0.120 & 0.031 & 0.46 & 0.034 & 0.225 & 0.057 & 0.897 \\
\hline Chemotherapy & 0.232 & 0.484 & 0.147 & 1.592 & 0.184 & 0.407 & 0.108 & 1.535 \\
\hline Cancer history & 0.962 & 0.964 & 0.215 & 4.325 & 0.581 & 1.793 & 0.226 & 14.26 \\
\hline \multirow[t]{2}{*}{ Dkk-3 expression } & 0.004 & 29.631 & 2.965 & 296.135 & 0.010 & 11.282 & 1.785 & 71.291 \\
\hline & \multicolumn{4}{|c|}{ Metastasis-free survival } & \multicolumn{4}{|c|}{ Recurrence-free survival } \\
\hline \multirow[t]{2}{*}{ Variables } & $\mathrm{p}$-value & HR & \multicolumn{2}{|c|}{$95 \% \mathrm{CI}$} & p-value & HR & \multicolumn{2}{|c|}{$95 \% \mathrm{CI}$} \\
\hline & & & Lower & Upper & & & Lower & Upper \\
\hline Gender & 0.242 & 2.780 & 0.501 & 15.421 & 0.942 & 0.000 & 0.000 & $2.5 \mathrm{E} 131$ \\
\hline Age & 0.428 & 0.650 & 0.224 & 1.885 & 0.267 & 0.012 & 0.000 & 29.177 \\
\hline Smoking & 0.820 & 1.225 & 0.212 & 7.061 & 0.904 & 2.348E8 & 0.000 & $1.0 \mathrm{E} 145$ \\
\hline Alcohol & 0.120 & 0.402 & 0.128 & 1.266 & 0.997 & 1.855 & 0.000 & $1.1 \mathrm{E} 132$ \\
\hline TNM stage & 0.935 & 0.000 & 0.000 & 5367E112 & 0.815 & 0.000 & 0.000 & $2.6 \mathrm{E} 161$ \\
\hline T stage & 0.942 & 22231.109 & 0.000 & $9.71 \mathrm{E} 121$ & 0.898 & $1.142 \mathrm{E} 11$ & 0.000 & $9.8 \mathrm{E} 179$ \\
\hline $\mathrm{N}$ stage & 0.260 & 2.805 & 0.467 & 16.867 & 0.853 & 461597.142 & 0.000 & 4.13E65 \\
\hline Differentiation & 0.378 & 1.845 & 0.473 & 7.195 & 0.739 & $6.062 \mathrm{E} 9$ & 0.000 & 2.73E67 \\
\hline Radiation & 0.002 & 0.112 & 0.028 & 0.446 & 0.945 & 36.285 & 0.000 & $8.26 \mathrm{E} 45$ \\
\hline Chemotherapy & 0.706 & 0.777 & 0.210 & 2.884 & 0.746 & 0.000 & 0.000 & 6.37E48 \\
\hline Cancer history & 0.868 & 0.881 & 0.200 & 3.894 & 0.968 & 4601.361 & 0.000 & $9.8 \mathrm{E} 180$ \\
\hline Dkk-3 expression & 0.015 & 17.774 & 1.755 & 179.986 & 0.362 & 5000.076 & 0.000 & 4.43E11 \\
\hline
\end{tabular}

HR, Hazard ratio; CI, confidence interval. TNM, tumor node metastasis.

for specific and powerful genes or pathways in HNSCC has been ongoing.

We focused on $\mathrm{Wnt} / \beta$-catenin signaling and its negative regulator molecules as one of the most promising targets. Wnt/ $\beta$-catenin signaling is tightly regulated by antagonists, such as the Dkk family, Wnt inhibitory factor (WIF) and secreted frizzled related protein (sFRP). When Wnt ligands bind to their receptor complex, frizzled and LRP5/6, $\beta$-catenin translocation into the nucleus occurs, resulting in the transcription of c-myc, c-jun, fra-1 and cyclin D1 (19). In cancer conditions, the aberrant expression of Wnt or down-regulation of Wnt antagonists has been repeatedly reported in several types of malignancy (20-22). Further investigation has revealed that down-regulation of Dkk-3 in cancers was due to epigenetic silencing by DNA methylation (23-28). However, paradoxically, Dkk-3 has been found to be overexpressed in hepatoblastomas and hepatocellular carcinomas (29), suggesting that the function of Dkk-3 may differ depending on the tissue of origin. Moreover, to the best of our knowledge, Dkk-3 expression in HNSCC has not yet been reported. Based on this fact, we firstly investigated Dkk-3 protein expression in a large number of HNSCC tissue samples and cell lines, and assessed the correlation between Dkk-3 protein expression and clinical aspects.

Notably, our data varied from those of previous studies of other malignancies, suggesting that Dkk-3 may not act as a tumor suppressor in HNSCC. Results of the Western blot analysis revealed that all the cell lines studied (10/10) exhibited a positive reaction to a varying degree. Dkk-3 expression is present in primary and metastatic cancer. These data suggest 
that Dkk-3 DNA methylation is not likely to be involved in HNSCC carcinogenesis, whereas this event is common in other organs. Reflecting the protein expression in cell lines, $84.4 \%$ (76/90) of HNSCC tissue samples demonstrated Dkk-3 expression. Supporting our data, certain reports $(16,17)$ have noted Dkk-3 expression in esophageal squamous cell carcinoma. As for Dkk-3 expression in cancer cell lines, it is reported that 8 out of the 13 cell lines expressed Dkk- 3 mRNA, and that its protein expression was also conserved in $16.9 \%$ of the esophageal squamous cell carcinoma tissue samples (16). Recently, Dkk-3 has been reported to be expressed and up-regulated in esophageal squamous cell carcinoma (17). Taken together, specific Dkk-3 expression is thought to be a common event in squamous epithelium in the head and neck region, which would be a significant and noteworthy finding in understanding the biological characteristics of HNSCC.

In addition, we have examined the association between Dkk-3 expression and clinicopathological characteristics together with survival analyses to gain a better understanding of the specific Dkk-3 expression in HNSCC. The patients were divided into two groups based on the Dkk-3 expression profile, Dkk-3 (+) and Dkk-3 (-). The Chi-square test results revealed no significant correlation between Dkk-3 expression and the clinicopathological parameters (Table II). A comparison was made of the DFS and OS between the Dkk-3 (+) and Dkk-3 (-) groups. The Dkk-3 (-) group tended to show longer OS $(\mathrm{p}=0.155)$ and significantly longer DFS $(\mathrm{p}=0.038)$. MFS of the Dkk-3 (-) group was significantly longer than that of the Dkk-3 (+) group $(\mathrm{p}=0.013)$, whereas RFS showed no significant difference between the two groups. Thus, this longer MFS may contribute to longer DFS in the Dkk-3 (-) group.

The patient group includes numerous confounding factors, including varying tumor stage, lymph nodal status, chemotherapy and/or radiation therapy. Therefore, a Cox proportional hazard model analysis has been performed in order to exclude the bias to clarify whether Dkk-3 is an independent prognostic factor. The results showed that no Dkk-3 expression was an independent prognostic biomarker for DFS, OS and MFS $(\mathrm{p}=0.004, \mathrm{p}=0.010$ and $\mathrm{p}=0.015$, respectively), together with existence of radiation therapy (DFS, $\mathrm{p}=0.002$; OS, $\mathrm{p}=0.034$; and MFS, $\mathrm{p}=0.002$ ).

Taking into consideration the fact that Dkk-3 is a known tumor suppressor and that its expression is generally reduced in cancer tissues, our findings are thought to be relatively paradoxical. Moreover, our results demonstrate that the Dkk-3 (-) group did not experience lymph nodal/distant metastasis, and that Dkk-3 (-) patients have a significantly lower risk of presenting metastasis. This finding suggests that Dkk-3 may be involved in the metastatic process and may be used as a prognostic marker in HNSCC. In this context, Dkk-3 appears to act as an oncogene, playing a role in cancer metastasis in HNSCC.

The possibility of oncogenic properties of Dkk-3 has yet to be investigated. However, another finding in this study may aid the explanation of the current results. In the immunohistochemical analyses, Dkk-3 expression was also observed in the small blood/lymphatic vessels around the tumor nests. Recently, the vascular expression of Dkk-3 around cancer cells has become a topic of debate. Dkk-3 is reportedly up-regulated in the tumor endothelium of colorectal cancer. This augmentation of Dkk-3 expression is correlated with an increase in the number of microvessels, suggesting that Dkk-3 is a marker for neo-angiogenesis in colorectal cancer (30). Moreover, Untergasser et al demonstrated that the number of blood vessels expressing Dkk-3 is increased in glioma, high-grade non-Hodgkin's lymphoma, melanoma and colorectal cancer in comparison with the blood vessels located in non-tumor tissues. Overexpression or inhibition of Dkk-3 in endothelial colonyforming cells does not affect their proliferation or migration, but tube formation in matrigel may increase following Dkk-3 overexpression and decrease following Dkk-3 down-regulation (31). Thus, it is possible that Dkk-3 may be a differentiation factor involved in the remodeling of the tumor vasculature. Neo-angiogenesis is critical for tumor growth (32-34) and improved prognosis for patients without Dkk-3 in HNSCC may be correlated to the effect of Dkk-3 on tumor vasculature. Such hypotheses may also be in agreement with the significant relationship found between Dkk-3 and metastasis.

In conclusion, we have shown that Dkk-3 expression is conserved in HNSCC, and that this expression may be used as a prognostic factor for metastasis risk in HNSCC. In the present study, we confirmed a noteworthy phenomenon. However, the detailed functions of Dkk-3 and the mechanism pertaining to why Dkk-3 is specifically conserved in HNSCC remains unclear. Further investigation including functional analyses may clarify these points

\section{Acknowledgements}

This work was partially supported by a grant-in-aid for scientific researches from the Ministry of Education, Culture, Sports, Science and Technology (Japan), 22791766 (to N.K.), 22•00130 (to M.L.), 20791515 (to H.T.) and 21592326 (to H.N.).

\section{References}

1. Ha PK, Chang SS, Glazer CA, Califano JA and Sidransky D: Molecular techniques and genetic alterations in head and neck cancer. Oral Oncol 45: 335-339, 2009.

2. Gunduz M, Ouchida M, Fukushima K, Hanafusa H, Etani T, Nishioka S, Nishizaki K and Shimizu K: Genomic structure of the human ING1 gene and tumor-specific mutations detected in head and neck squamous cell carcinomas. Cancer Res 60: 3143-3146, 2000 .

3. Gunduz M, Ouchida M, Fukushima K, Ito S, Jitsumori Y, Nakashima T, Nagai N, Nishizaki K and Shimizu K: Allelic loss and reduced expression of the ING3, a candidate tumor suppressor gene at 7q31, in human head and neck cancers. Oncogene 21: 4462-4470, 2002.

4. Gunduz M, Nagatsuka H, Demircan K, Gunduz E, Cengiz B, Ouchida M, Tsujigiwa H, Yamachika E, Fukushima K, Beder L, et al: Frequent deletion and down-regulation of ING4, a candidate tumor suppressor gene at $12 \mathrm{p} 13$, in head and neck squamous cell carcinomas. Gene 356: 109-117, 2005.

5. Cengiz B, Gunduz E, Gunduz M, Beder LB, Tamamura R, Bagci C, Yamanaka N, Shimizu K and Nagatsuka H: Tumor specific mutation and downregulation of ING5 detected in oral squamous cell carcinoma. Int J Cancer 127: 2088-2094, 2010

6. Borkosky SS, Gunduz M, Nagatsuka H, Beder LB, Gunduz E, Ali MA, Rodriguez AP, Cilek MZ, Tominaga S, Yamanaka N, Shimizu $\mathrm{K}$ and Nagai N: Frequent deletion of ING2 locus at 4q35.1 associates with advanced tumor stage in head and neck squamous cell carcinoma. J Cancer Res Clin Oncol 135: 703-713, 2009.

7. Katase N, Gunduz M, Beder L, Gunduz E, Lefeuvre M, Hatipoglu OF, Borkosky SS, Tamamura R, Tominaga S, Yamanaka N, et al: Deletion at Dickkopf (dkk)-3 locus (11p15.2) is related with lower lymph node metastasis and better prognosis in head and neck squamous cell carcinomas. Oncol Res 17: 273-282, 2008 
8. Katase N, Gunduz M, Beder LB, Gunduz E, Al Sheikh Ali M, Tamamura R, Yaykasli KO, Yamanaka N, Shimizu K and Nagatsuka H: Frequent allelic loss of Dkk-1 locus (10q11.2) is related with low distant metastasis and better prognosis in head and neck squamous cell carcinomas. Cancer Invest 28: 103-110 2010.

9. Song J, Chang I, Chen Z, Kang M and Wang CY: Characterization of side population in HNSCC: highly invasive, chemoresistant and abnormal Wnt signaling. PLoS One 5: e11456, 2010.

10. Lee EJ, Jo M, Rho SB, Park K, Yoo YN, Park J, Chae M, Zhang W and Lee JH: Dkk3, downregulated in cervical cancer, functions as a negative regulator of beta-catenin. Int J Cancer 124: 287-297, 2009.

11. Mizobuchi Y, Matsuzaki K, Kuwayama K, Kitazato K, Mure H, Kageji T and Nagahiro S: REIC/Dkk-3 induces cell death in human malignant glioma. Neuro Oncol 10: 244-253, 2008.

12. Yang B, Du Z, Gao YT, Lou C, Zhang SG, Bai T, Wang YJ and Song WQ: Methylation of Dickkopf-3 as a prognostic factor in cirrhosis-related hepatocellular carcinoma. World J Gastroenterol 16: 755-763, 2010.

13. Veeck J, Wild PJ, Fuchs T, Schüffler PJ, Hartmann A, Knüchel R and Dahl E: Prognostic relevance of Wnt-inhibitory factor-1 (WIF1) and Dickkopf-3 (DKK3) promoter methylation in human breast cancer. BMC Cancer 9: 217, 2009.

14. Kuphal S, Lodermeyer S, Bataille F, Schuierer M, Hoang BH and Bosserhoff AK: Expression of Dickkopf genes is strongly reduced in malignant melanoma. Oncogene 25: 5027-5036, 2006.

15. Zenzmaier C, Untergasser G, Hermann M, Dirnhofer S, Sampson N and Berger P: Dysregulation of Dkk-3 expression in benign and malignant prostatic tissue. Prostate 68: 540-547, 2008.

16. Maehata T, Taniguchi H, Yamamoto H, Nosho K, Adachi Y, Miyamoto N, Miyamoto C, Akutsu N, Yamaoka S and Itoh F: Transcriptional silencing of Dickkopf gene family by $\mathrm{CpG}$ island hypermethylation in human gastrointestinal cancer. World J Gastroenterol 14: 2702-2714, 2008.

17. Zhang Y, Dong WG, Yang ZR, Lei XF and Luo HS: Expression of Dickkopf-3 in esophageal squamous cell carcinoma. Zhonghua Nei Ke Za Zhi 49: 325-327, 2010.

18. Yamachika E, Tsujigiwa H, Shirasu N, Ueno T, Sakata Y, Fukunaga J, Mizukawa N, Yamada M and Sugahara T: Immobilized recombinant human bone morphogenetic protein-2 enhances the phosphorylation of receptor-activated Smads. J Biomed Mater Res A 88: 599-607, 2009.

19. Kikuchi A, Kishida S and Yamamoto H: Regulation of Wnt signaling by protein-protein interaction and post-translational modifications. Exp Mol Med 38: 1-10, 2006.

20. Kurayoshi M, Oue N, Yamamoto H, Kishida M, Inoue A Asahara T, Yasui W and Kikuchi A: Expression of Wnt-5a is correlated with aggressiveness of gastric cancer by stimulating cell migration and invasion. Cancer Res 66: 10439-10448, 2006.

21. Sato H, Suzuki H, Toyota M, Nojima M, Maruyama R, Sasaki S, Takagi H, Sogabe Y, Sasaki Y, Idogawa M, et al: Frequent epigenetic inactivation of DICKKOPF family genes in human gastrointestinal tumors. Carcinogenesis 28: 2459-2466, 2007.
22. Suzuki H, Toyota M, Carraway H, Gabrielson E, Ohmura T, Fujikane T, Nishikawa N, Sogabe Y, Nojima M, Sonoda T, et al: Frequent epigenetic inactivation of Wnt antagonist genes in breast cancer. Br J Cancer 98: 1147-1156, 2008

23. Götze S, Wolter M, Reifenberger G, Müller O and Sievers S: Frequent promoter hypermethylation of Wnt pathway inhibitor genes in malignant astrocytic gliomas. Int J Cancer 126: 2584-2593, 2010

24. Ding Z, Qian YB Zhu LX and Xiong QR: Promoter methylation and mRNA expression of Dkk-3 and WIF-1 in hepatocellular carcinoma. World J Gastroenterol 15: 2595-2601, 2009.

25. Fujikane T, Nishikawa N, Toyota M, Suzuki H, Nojima M, Maruyama R, Ashida M, Ohe-Toyota M, Kai M, Nishidate T, et al: Genomic screening for genes upregulated by demethylation revealed novel targets of epigenetic silencing in breast cancer. Breast Cancer Res Treat 122: 699-710, 2010.

26. Veeck J, Bektas N, Hartmann A, Kristiansen G, Heindrichs U, Knüchel R and Dahl E: Wnt signaling in human breast cancer: expression of the putative Wnt inhibitor Dickkopf-3 (DKK3) is frequently suppressed by promoter hypermethylation in mammary tumours. Breast Cancer Res 10: R82, 2008.

27. Licchesi JD, Westra WH, Hooker CM, Machida EO, Baylin SB and Herman JG: Epigenetic alteration of Wnt pathway antagonists in progressive glandular neoplasia of the lung. Carcinogenesis 29: 895-904, 2008 .

28. Hirata H, Hinoda Y, Nakajima K, Kikuno N, Yamamura S, Kawakami K, Suehiro Y, Tabatabai ZL, Ishii N and Dahiya R: Wnt antagonist gene polymorphisms and renal cancer. Cancer 115: 4488-4503, 2009.

29. Pei Y, Kano J, Ijijima T, Morishita Y, Inadome Y and Noguchi M: Overexpression of Dickkopf 3 in hepatoblastomas and hepatocellular carcinomas. Virchows Arch 454: 639-646, 2009.

30. Zitt M, Untergasser G, Amberger A, Moser P, Stadlmann S, Zitt M, Müller HM, Mühlmann G, Perathoner A, Margreiter R, Gunsilius E and Ofner D: Dickkopf-3 as a new potential marker for neoangiogenesis in colorectal cancer: expression in cancer tissue and adjacent non-cancerous tissue. Dis Markers 24: 101-109, 2008.

31. Untergasser G, Steurer M, Zimmermann M, Hermann M, Kern J, Amberger A, Gastl G and Gunsilius E: The Dickkopf-homolog 3 is expressed in tumor endothelial cells and supports capillary formation. Int J Cancer 122: 1539-1547, 2008.

32. Folkman J, Bach M, Rowe JW, Davidoff F, Lambert P, Hirsch C, Goldberg A, Hiatt HH, Glass J and Henshaw E: Tumor angiogenesis - therapeutic implications. N Engl J Med 285: 1182-1186, 1971.

33. Bergers $G$ and Benjamin LE: Tumorigenesis and the angiogenic switch. Nat Rev Cancer 3: 401-410, 2003.

34. Carmeliet P and Jain RK: Angiogenesis in cancer and other diseases. Nature 407: 249-257, 2000 